\title{
A Constituição Federal de 1988 face as emendas constitucionais correlatas à educação ${ }^{1}$
}

The Federal Constitution of 1988 and the constitutional changes related to education

La Constitution Fédérale de 1988 et les amendements constitutionnels relatifs à l'éducation

Marli dos Santos de Oliveira ${ }^{2}$

Maria Dilnéia Espíndola Fernandes ${ }^{3}$ Universidade Federal de Mato Grosso do Sul

Resumo: $\mathrm{O}$ artigo busca desvelar as prerrogativas constitucionais destinadas à educação escolar enquanto um direito social, por meio de pesquisa bibliográfica e documental. A previsão da educação enquanto direito social na Constituição Federal de 1988 apresenta-se como inegável avanço no campo das políticas sociais. Os trinta anos de vigência da Constituição Federal foram marcados pela aprovação de diversas Emendas para o campo dos direitos sociais. Nesse contexto, o artigo destaca a aprovação da Emenda Constitucional n. 95 de 2016, dado o caráter de regressão aos direitos sociais que a mesma impõe.

Palavras-chaves: Política educacional. Direito à educação. Constituição Federal de 1988. Emendas Constitucionais.

Abstract: The article seeks to unveil the constitutional prerogatives for school education as a social right, through bibliographical and documentary research. The prediction of education as a social right in the Federal Constitution of 1988 presents itself as an undeniable advance in the field of social policies. The thirty years of validity of the Federal Constitution were marked by the approval of several amendments to the field of social rights. In this context, the article highlights the approval of Constitutional Amendment $\mathrm{n}$. 95 of 2016 , given the regressive nature of the social rights that it imposes.

1 Este trabalho foi apresentado em primeiro momento no "X Seminário de Política e Administração da Educação - ANPAE Centro-Oeste: Educação e Democracia: políticas e direitos sociais”, realizado de 14 a 16 de agosto de 2018, em Campo Grande, MS. O artigo incorpora resultados do debate ocorrido a partir de sua apresentação no evento em questão. O trabalho integra a Pesquisa "Planos Municipais de Educação no alinhamento com o PNE 2014-2024”.

2 Mestre em Educação pela Universidade Federal da Grande Dourados. Doutoranda em Educação no Programa de Pós-Graduação em Educação da Universidade Federal de Mato Grosso do Sul.E-mail:marli.oliveiras@hotmail.com

3 Doutora em Educação pela Universidade Estadual de Campinas. Professora Titular da Universidade Federal de Mato Grosso do Sul na Faculdade de Educação. Professora Credenciada no Programa de Pós-Graduação da Universidade Federal de Mato Grosso do Sul. Bolsista Produtividade em Pesquisa do CNPq.E-mail:mdilneia@uol.com.br 
Keywords: Educational politics. Right to education. Federal Constitution of 1988. Constitutional Amendments.

Sommaire: L'article cherche à dévoiler les prérogatives constitutionnelles de l'éducation scolaire en tant que droit social, à travers des recherches bibliographiques et documentaires. La prédiction de l'éducation en tant que droit social dans la Constitution fédérale de 1988 se présente comme un progrès indéniable dans le domaine des politiques sociales. Les trente années de validité de la Constitution fédérale ont été marquées par l'approbation de plusieurs amendements dans le domaine des droits sociaux. Dans ce contexte, l'article met en évidence l'approbation de l'amendement constitutionnel n. 95 de 2016, compte tenu du caractère régressif des droits sociaux qu'il impose.

Mots-Clés: Politique éducative. Droit à l'éducation Constitution fédérale de 1988. Amendements constitutionnels.

\section{Considerações iniciais}

Em de 05 de outubro de 2018 comemorar-se-á os 30 (trinta) anos de promulgação da Constituição da República Federativa do Brasil de 1988 (CF/1988). Diferentes áreas do conhecimento, sobretudo às Ciências Sociais Aplicadas e Ciências Humanas (re) direcionam seus objetos de análise a fim de analisar os fenômenos sociais no contexto dessas três décadas da promulgação da "Constituição Cidadã".

No bojo de seus princípios fundamentais, a CF/1988 estabelece que a República Federativa do Brasil constitui-se em Estado Democrático de Direito Social, cujos fundamentos são a soberania, a cidadania, a dignidade da pessoa humana, os valores sociais do trabalho, bem como o pluralismo político.

O título de Constituição Cidadã advém, entre outros aspectos, pelo rol estabelecido em seu Título II "Dos Direitos e Garantias Fundamentais", cujos Art. $5^{\circ}$ e Art. $6^{\circ}$, especialmente, preconizam taxativamente garantias fundamentais individuais e coletivas, bem como o rol de direitos sociais, cuja previsão constitucional representa inegável importância. "Direitos fundamentais são direitos público-subjetivos de pessoas (físicas ou jurídicas), contidos em dispositivos constitucionais e, portanto, que encerram caráter normativo supremo dentro do Estado" […] (DIMOULIS, MARTINS, 2014, p.41).

Nesse contexto, não se pode desconsiderar, todavia, a trajetória pré-constituinte que possibilitou a constitucionalização de demandas e anseios de diferentes movimentos sociais e, 
em particular, dos educadores e entidades ligadas à educação, que travaram embates a fim de garantir uma série de prerrogativas, entre as quais, estão: a inclusão da educação infantil como primeira etapa da educação básica, a previsão do princípio da gestão democrática da educação pública, a definição do município como ente federado, a definição de competências privativas e concorrentes entre os entes subnacionais, entre outros dispositivos.

Nesse contexto, busca-se compreender as prerrogativas constitucionais destinadas à educação escolar enquanto um direito social constitucionalmente garantido. A premissa é que a previsão da educação enquanto direito social apresenta-se como inegável avanço no campo das políticas sociais, no entanto, determinadas mudanças jurídico-políticas consubstanciadas em Emendas Constitucionais, sinalizam retrocessos no tocante aos direitos sociais em geral e, em particular, à educação.

\section{Educação como Direito Social na CF/1988 e às Emendas Constitucionais correlatas}

A proposta da Assembleia Nacional Constituinte, instalada oficialmente no dia primeiro de fevereiro de 1987, mobilizou a sociedade brasileira nos diversos segmentos e setores sociais. A educação foi um dos temas em torno dos quais diversas discussões e atividades foram realizadas com vistas a definir os princípios constitutivos da nova Carta Magna (PINHEIRO, 1996).

\footnotetext{
O método aprovado de elaboração da Constituição baseou-se em ouvir inicialmente as sugestões dos Constituintes, bem como de representantes da sociedade civil e do Estado, e com base nessa consulta, que resultaria na votação dos primeiros anteprojetos, construir o texto Constitucional. Os constituintes fariam suas propostas, ouviriam as demandas da sociedade civil e formulariam o projeto final de Constituição. Para esse fim, a ANC aprovou uma estrutura de funcionamento divida em quatro etapas: as Subcomissões, as Comissões Temáticas, a Comissão de Sistematização e o Plenário da Constituinte (PINHEIRO, 1996, p. 266).
}

A CF/1988 foi a mais detalhada das constituições brasileiras, regulando não apenas princípios, regras e direitos individuais, coletivos e sociais como também uma gama de políticas públicas (Souza, 2005). Em seu Art. 18 traz que “A organização políticoadministrativa da República Federativa do Brasil compreende a União, os Estados e os Municípios, todos autônomos, nos termos desta Constituição”. Em seu Art. 60, consideradas as cláusulas pétreas constitucionais, dispõe que não será objeto de deliberação a proposta de emenda tendente a abolir a forma federativa de Estado. 
Nota-se que a estruturação federativa brasileira é efetivada sob o princípio da cooperação recíproca, sendo que, ao invés de um sistema dualista, hierárquico e/ou centralizado a Constituição delega competências e atribuições legislativas entre os integrantes do sistema federativo tendo em vista os limites expressos, de modo a reconhecer a dignidade e a autonomia própria dos entes subnacionais (Cury, 2006).

Registre-se ainda que o reconhecimento do município como ente federativo, que passou a ser regido por lei orgânica elaborada por seu respectivo poder legislativo, representa uma mudança jurídico-política de grande significado na história brasileira (Fernandes, 2008). A partir de meados dos anos de 1990 os governos locais se tornaram os principais provedores de direitos referentes à saúde e educação fundamental, com vistas a garantir aos cidadãos, padrões mínimos de atendimento desses direitos.

A disposição constitucional que reconhece os municípios como ente federativo, estabeleceu um regime normativo e político descentralizado e plural, no qual se cruzam e se complexificam novos e diferentes mecanismos de participação e prestação dos direitos públicos.

Notadamente acerca do reconhecimento da Educação como um Direito Social, a CF/1988 dispõe que: Art. $6^{\circ}$ São direitos sociais a educação, a saúde, a alimentação, o trabalho, a moradia, o transporte, o lazer, a segurança, a previdência social, a proteção a maternidade e à infância, a assistência aos desamparados, na forma desta Constituição (Brasil, 1988). É importante registrar que a compreensão dos Direitos Sociais prescinde a análise conjunta e sistemática de todas as normas constitucionais a eles vinculadas direta e indiretamente, bem como da legislação infraconstitucional e jurisprudência que os viabiliza (SARLET, MARINONI, MITIDIERO, 2017).

Além da previsão no Art. $6^{\circ}$, a CF/1988 é a primeira a destinar um capítulo específico à educação. Os artigos 205 a 214 estabelecem princípios que devem ser observados no ensino, tais como o pluralismo de ideias e a gestão democrática, a autonomia didáticocientífica, administrativa e de gestão das universidades, o dever do Estado na garantia de educação básica obrigatória e gratuita dos 4 (quatro) aos 17 (dezessete), programas suplementares, percentuais a serem empreendidos pelos entes subnacionais e a previsão de Plano Nacional de Educação.

As normas constitucionais vinculadas diretamente à educação destinam-se a variados aspectos pedagógicos, administrativos e de gestão, cuja previsão, seja no texto original, ou no contexto das alterações por meio das Emendas à Constituição, refletem determinados 
anseios julgados fundamentais, em determinado momento histórico, por determinados grupos.

O caminho de efetivação dos preceitos constitucionais destinados à garantia da educação como um Direito Social requer mecanismos de proteção com vistas a garantir, da melhor forma possível, sua efetividade no plano jurídico e social. Sobre isso, é importante destacar as considerações de Sarlet, Marinoni e Mitidiero (2017) acerca do Princípio da Proibição de retrocesso aos Direitos Sociais, cuja proteção relaciona-se em face do legislador, bem como diante de atos administrativos dos poderes. Tem-se, portanto,

[...] a proibição jurídico-constitucional de retrocesso, como mecanismo de controle para coibir e/ou corrigir medidas restritivas ou mesmo supressivas de direitos sociais [...] que, mediante a revogação ou alteração da legislação infraconstitucional (apenas para citar uma forma de intervenção nos direitos sociais), venham a desconstituir ou afetar gravemente o grau de concretização já atribuído a determinado direito fundamental (e social), o que equivaleria a uma violação da própria Constituição Federal e de direitos fundamentais nela consagrados. (IBID, 2017, p.619).

A análise acerca da proibição de retrocesso vincula-se, por consequência, ao dever da progressiva expansão dos Direitos Sociais, visto que, sem os avanços necessários, a prestação dos serviços públicos envolvendo tais diretos torna-se inadequada e fere, portanto, a disposição do Art. $5^{\circ}, \$^{\circ}$ da $\mathrm{CF} / 1988$ que determina máxima observância e aplicabilidade às normas definidoras de direitos e garantias fundamentais.

O título de Constituição Cidadã em sintonia com o Princípio da proibição de retrocessos não tem sido observado e garantido em determinados contextos históricos, se observadas às reformas constitucionais empreendidas, bem como a instabilidade da segurança jurídica. A defesa e a supremacia da Constituição devem ser observadas pelos sujeitos e, conforme o Art. $1^{\mathrm{o}}$ do Ato das Disposições Constitucionais Transitórias, “o Presidente da República, o presidente do Supremo Tribunal Federal e os membros do Congresso Nacional prestarão o compromisso de manter, defender e cumprir a Constituição, no ato e na data de sua promulgação".

No entanto, uma breve análise acerca da defesa e/ou alteração das normas das Constituições brasileiras, permite inferir que a $\mathrm{CF} / 1988$, além do destaque em relação às demais constituições pela garantia de direitos fundamentais, tem se destacado, pelo quantitativo de Emendas, como se nota na Tabela 01:

Tabela 01: Informações gerais sobre as Constituições do Brasil 


\begin{tabular}{|c|c|c|c|}
\hline $\begin{array}{c}\text { CONSTITUIÇÕES } \\
\text { BRASILEIRAS }\end{array}$ & $\begin{array}{c}\text { FIM DE } \\
\text { VIGÊNCIA }\end{array}$ & $\begin{array}{c}\text { NÚUMRO DE } \\
\text { EMENDAS }\end{array}$ & DURAÇÃO \\
\hline $\begin{array}{c}\text { Constituição de 1824 } \\
\text { (Brasil Império) }\end{array}$ & 1889 & 1 & 65 anos \\
\hline $\begin{array}{c}\text { Constituição de 1891 } \\
\text { (Brasil República) }\end{array}$ & 1930 & 1 & 39 anos \\
\hline $\begin{array}{c}\text { Constituição de 1934 } \\
\text { (Segunda República) }\end{array}$ & 1937 & 21 & 8 anos \\
\hline $\begin{array}{c}\text { Constituição de 1937 } \\
\text { (Estado Novo) }\end{array}$ & 1945 & 27 & 21 anos \\
\hline $\begin{array}{c}\text { Constituição de 1946 } \\
\text { (Redemocratização) }\end{array}$ & 1967 & & 20 anos \\
\hline $\begin{array}{c}\text { Constituição de 1967 } \\
\text { (Regime Militar) }\end{array}$ & 1987 & $99^{4}$ & 30 anos \\
\hline $\begin{array}{c}\text { Constituição de 1988 } \\
\text { (Constituição Cidadã) }\end{array}$ & Em vigor & & \\
\hline
\end{tabular}

Fonte: Elaboração própria com base em Nogueira (2012), Brasil (2018).

Nota-se, portanto, que os últimos textos constitucionais, pós Estado Novo, têm recebido o maior quantitativo de Emendas. Em determinadas situações, essas alterações fazem-se necessárias a fim de compatibilizar as normas legais aos anseios sociais. No entanto, tais alterações que deveriam ser excepcionais, têm ocorrido com demasiada frequência, sobretudo se observado as 99 (noventa e nove) Emendas à CF/1988 antes mesmo de completar três décadas de promulgação.

Notadamente acerca das Emendas que alteraram as disposições constitucionais previstas no Capítulo III destinado à educação, tem-se a Tabela 02 a seguir:

Tabela 02: Emendas Constitucionais que alteraram a Seção I, Capítulo III da CF/1988.

\begin{tabular}{|c|l|}
\hline EMENDA CONSTITUCIONAL & \multicolumn{1}{|c|}{ EMENTA } \\
\hline $\begin{array}{c}\text { EC N } \mathrm{N}^{\circ} 1 \text {, de 30.04.1996 } \\
\text { Publicado no DOU 02.05.1996 }\end{array}$ & $\begin{array}{l}\text { Permite a admissão de professores, técnicos e } \\
\text { cientistas estrangeiros pelas universidades } \\
\text { brasileiras e concede autonomia às instituições }\end{array}$ \\
\hline
\end{tabular}

4. Dados relativos à consulta realizada em 20 de junho de 2018 no endereço: <http://www.planalto.gov.br/ccivil_03/constituicao/emendas/emc/quadro_emc.htm>. 


\begin{tabular}{|c|c|}
\hline & de pesquisa científica e tecnológica. \\
\hline $\begin{array}{c}\mathrm{EC} \mathrm{N}^{\circ} \text { 14, de 12.09.1996 } \\
\text { Publicado no DOU 13.09.1996 }\end{array}$ & $\begin{array}{l}\text { Modifica os arts. 34, 208, } 211 \text { e } 212 \text { da } \\
\text { Constituição Federal e dá nova redação ao art. } \\
60 \text { do Ato das Disposições constitucionais } \\
\text { Transitórias. }\end{array}$ \\
\hline $\begin{array}{c}\mathrm{EC} \mathrm{N}^{\circ} \text { 53, de 19.12.2006 } \\
\text { Publicado no DOU 20.12.2006 }\end{array}$ & $\begin{array}{l}\text { Dá nova redação aos arts. } 7^{\circ}, 23,30,206,208 \text {, } \\
211 \text { e } 212 \text { da Constituição Federal e ao art. } 60 \\
\text { do Ato das Disposições Constitucionais } \\
\text { Transitórias. }\end{array}$ \\
\hline $\begin{array}{c}\mathrm{EC} \mathrm{N}^{\circ} \text { 59, de } 11.11 .2009 \\
\text { Publicado no DOU 12.11.2009 }\end{array}$ & $\begin{array}{l}\text { Acrescenta } \$ 3^{\circ} \text { ao art. } 76 \text { do Ato das } \\
\text { Disposições Constitucionais Transitórias para } \\
\text { reduzir, anualmente, a partir do exercício de } \\
2009 \text {, o percentual da Desvinculação das } \\
\text { Receitas da União incidente sobre os recursos } \\
\text { destinados à manutenção e desenvolvimento do } \\
\text { ensino de que trata o art. } 212 \text { da Constituição } \\
\text { Federal, dá nova redação aos incisos I e VII do } \\
\text { art. 208, de forma a prever a obrigatoriedade } \\
\text { do ensino de quatro a dezessete anos e ampliar } \\
\text { a abrangência dos programas suplementares } \\
\text { para todas as etapas da educação básica, e dá } \\
\text { nova redação ao } \$ 4^{\circ} \text { do art. } 211 \text { e ao } \S 3^{\circ} \text { do } \\
\text { art. } 212 \text { e ao caput do art. } 214 \text {, com a inserção } \\
\text { neste dispositivo de inciso VI. }\end{array}$ \\
\hline $\begin{array}{c}\mathrm{EC} \mathrm{N}^{\circ} \text { 85, de 26.2.2015 } \\
\text { Publicado no DOU 27.2.2015 }\end{array}$ & $\begin{array}{l}\text { Altera e adiciona dispositivos na Constituição } \\
\text { Federal para atualizar o tratamento das } \\
\text { atividades de ciência, tecnologia e inovação. }\end{array}$ \\
\hline
\end{tabular}

Fonte: Elaboração própria com base em Brasil (1988), Brasil (2018).

As Emendas compreendidas na Tabela 02 refletem mudanças significativas na dinâmica jurídico-social da educação. Interessante seria uma análise detida a fim de verificar os reflexos que essas alterações provocaram, seja no aspecto didático-pedagógico como, sobretudo, no que infere na progressiva efetivação e avanço dos Direitos Sociais, sobretudo à educação.

No entanto, dada à amplitude de discussões que tais emendas ensejam, limita-se no presente texto, às mudanças substanciais advindas com as Emendas Constitucionais $\mathrm{n}^{\mathrm{o}} 14 \mathrm{de}$ 1996, $\mathrm{n}^{\mathrm{o}} 53$ de 2006, $\mathrm{n}^{\mathrm{o}} 59$ de 2009 e n 85 de 2015 respectivamente e, na sequência, têm-se maiores reflexões acerca dos retrocessos provocados com Emenda Constitucional $\mathrm{n}^{\mathrm{o}} 95$ de 2016.

Notadamente acerca da EC $\mathrm{n}^{\circ} 14$ de 1996, a novidade inserida no ordenamento jurídico relaciona-se à inclusão da função redistributiva e supletiva da União, com vistas à 
garantia da equalização de oportunidades educacionais e padrão mínimo de qualidade de ensino, mediante assistência técnica e financeira aos demais entes subnacionais.

Outra novidade no capítulo da Educação trazida pela referida EC n ${ }^{\circ} 14$ de 1996, articula-se ao reconhecimento do município como ente federativo. Define-se, portanto, a competência de atuação do município no atendimento ao ensino fundamental e à educação infantil, entendida no contexto de creche e pré-escola e não apenas pré-escolar como era antes da $\mathrm{EC} \mathrm{n}^{\circ} 14$ de 1966.

Além de alterar o Art. 60 do ADCT da $\mathrm{CF} / 1988$, que previa utilização dos recursos constitucionais dos poderes públicos para erradicação do analfabetismo e universalização do ensino fundamental, no prazo de dez anos de vigência da CF/1988, a referida $\mathrm{EC} \mathrm{n}^{\circ} 14$ de 1996 criou o Fundo de Manutenção e Desenvolvimento do Ensino Fundamental e de Valorização do Magistério (FUNDEF), também com um prazo de vigência previsto para dez anos.

Em relação à $\mathrm{EC} \mathrm{n}^{\circ} 53$ de 2006, têm-se a alteração dos princípios que o ensino deve observar, dispostos no Art. 206, de modo a incluir a valorização e os planos de carreira, na forma da lei, a todos os profissionais da educação e não apenas aos do magistério. Além disso, houve a inclusão do inciso "VII - piso salarial profissional nacional para os profissionais da educação escolar pública, nos termos de lei federal” (BRASIL, 1988).

A EC n ${ }^{\circ} 53$ de 2006 define que o público alvo da educação infantil são as crianças de até 5 (cinco) anos de idade e altera o $\$ 5^{\circ}$ do Art. 212 para dispor que a fonte adicional de financiamento salário-educação destina-se à educação básica e não mais ao ensino fundamental, exclusivamente.

É importante registar que a EC n. ${ }^{\circ} 53$ de 2006, cria o Fundo de Manutenção e Desenvolvimento da Educação Básica e Valorização dos Profissionais da Educação (FUNDEB), em continuação ao FUNDEF que fora instituído pela EC nº 14 de 1996.

O Fundo de Manutenção e Desenvolvimento da Educação Básica e de Valorização dos Profissionais da Educação - Fundeb é um fundo especial, de natureza contábil e de âmbito estadual (um fundo por estado e Distrito Federal, num total de vinte e sete fundos), formado, na quase totalidade, por recursos provenientes dos impostos e transferências dos estados, Distrito Federal e municípios, vinculados à educação por força do disposto no art. 212 da Constituição Federal. Além desses recursos, ainda compõe o Fundeb, a título de complementação, uma parcela de recursos federais, sempre que, no âmbito de cada Estado, seu valor por aluno não alcançar o mínimo definido nacionalmente. Independentemente da origem, todo o recurso gerado é redistribuído para aplicação exclusiva na educação básica (Brasil, 2018, s.p). 
As EC nº 14 de 1996 e EC nº 53 de 2006 que instituíram o FUNDEF e o FUNDEB, respectivamente, formalizam reformas educacionais implementadas pelos governos de Fernando Henrique Cardoso e Luís Inácio Lula da Silva, de modo a instituir, segundo Oliveira (2009) a política de fundos sob o aspecto de distribuição de recursos e controle de gastos e também como recurso de regulação no contexto das ações federativas dos entes federativos.

A EC no 59 de 2009 por sua vez, representa uma alteração muito importante no tocante ao direito à educação: têm-se a obrigatoriedade da educação básica, compreendida a educação infantil (4 e 5 anos), o ensino fundamental ( 6 aos 14 anos) e o ensino médio (15 a 17 anos), assegurada a oferta gratuita inclusive aos que não tiveram acesso na idade própria.

Deste modo, a obrigatoriedade escolar diz respeito a faixa etária compreendida dos 4 (quatro) aos 17 (dezessete) anos, e não mais ao ensino fundamental obrigatório, conforme outrora. Garante-se, também, na forma da lei o atendimento aos estudantes da educação básica por meio de programas suplementares de alimentação, transporte escolar e material didático.

No tocante a histórica necessidade de articulação entre os sistemas de ensino, a EC n ${ }^{\circ}$ 59 de 2009 redefine as disposições do Art. 214 e estabelece que o Plano Nacional de Educação tenha duração decenal, e não mais plurianual, cujo objetivo é o de articular o sistema nacional de educação em regime de colaboração.

Essa articulação visa à definição de diretrizes, objetivos e metas com vistas ao desenvolvimento do ensino em seus níveis, etapas e modalidades. Nesse sentido, as ações integradas dos poderes públicos devem conduzir a diversas garantias, dentre as quais, fora incluído o "Art. 214, VI - estabelecimento de meta de aplicação de recursos públicos em educação como proporção do produto interno bruto" (Brasil, 1988).

A EC n 85 de 2015 estende a taxatividade do Art. 213 e dispõe que universidades e/ou instituições de educação profissional e tecnológica poderão receber apoio financeiro do Poder Público nas atividades de pesquisa, extensão e estímulo à inovação.

Além dessas Emendas, cumpre registrar que determinadas alterações legais, embora não ocorram diretamente no tex to dos artigos destinados à educação, refletem sobremaneira em sua materialização. Acerca disso, destacam-se as seguintes Emendas Constitucionais:

Tabela 03: Emendas Constitucionais que refletem na Seção I, Capítulo III da CF/1988. 


\begin{tabular}{|c|c|}
\hline EMENDA CONSTITUCIONAL & EMENTA \\
\hline $\begin{array}{c}\mathrm{EC} \mathrm{N}^{\mathrm{o}} \text { 84, de } 2.12 .2014 \\
\text { Publicado no DOU 3.12.2014 }\end{array}$ & $\begin{array}{l}\text { Altera o art. } 159 \text { da Constituição Federal para } \\
\text { aumentar a entrega de recursos pela União } \\
\text { para o Fundo de Participação dos Municípios. }\end{array}$ \\
\hline $\begin{array}{c}\mathrm{EC} \mathrm{N}^{\circ} 86, \text { de } 17.3 .2015 \\
\text { Publicado no DOU 18.3.2015 }\end{array}$ & $\begin{array}{l}\text { Altera os arts. } 165,166 \text { e } 198 \text { da Constituição } \\
\text { Federal, para tornar obrigatória a execução da } \\
\text { programação orçamentária que especifica. }\end{array}$ \\
\hline $\begin{array}{c}\mathrm{EC} \mathrm{N}^{\circ} \text { 93, de 8.9.2016 } \\
\text { Publicado no DOU 9.9.2016 - Edição } \\
\text { extra }\end{array}$ & $\begin{array}{l}\text { Altera o Ato das Disposições Constitucionais } \\
\text { Transitórias para prorrogar a desvinculação de } \\
\text { receitas da União e estabelecer a desvinculação } \\
\text { de receitas dos Estados, Distrito Federal e } \\
\text { Municípios. }\end{array}$ \\
\hline $\begin{array}{c}\mathrm{EC} \mathrm{N}^{\circ} \text { 95, de } 15.12 .2016 \\
\text { Publicado no DOU 16.12.2016 }\end{array}$ & $\begin{array}{l}\text { Altera o Ato das Disposições Constitucionais } \\
\text { Transitórias, para instituir o Novo Regime } \\
\text { Fiscal, e dá outras providências. }\end{array}$ \\
\hline
\end{tabular}

Fonte: Elaboração própria com base em Brasil (1988), Brasil (2018).

As ementas das Emendas Constitucionais supracitadas na Tabela 03 significam muitas controvérsias no contexto de materialização da educação como um Direito Social, sobretudo a $\mathrm{EC} \mathrm{n}^{\circ} 95$ de 2016. A Carta Magna de 1988 é considerada um marco no que se refere ao objetivo de construir uma sociedade democrática e socialmente justa, visto que inaugura um novo ciclo democrático que, aliado aos avanços sociais, contribui para melhorar o nível de vida da população brasileira, especialmente dos mais pobres (FAGNANI, 20 16).

Todavia, "Democracia” é um conceito em disputa, particularmente no Brasil, cujo resgate histórico evidencia que, no pós-guerra, somente três presidentes democraticamente eleitos (Juscelino Kubitschek, Fernando Henrique Cardoso e Luís Inácio Lula da Silva) terminaram seus respectivos mandatos (GOMES, 2016). Isso enseja que, no Brasil, a regra é o golpe e o autoritarismo, afinal, a tragédia de 1964 e a farsa de $2016^{5}$ têm em comum o ódio à democracia (LÖWI, 2016).

Tal farsa se refere à destituição da Presidenta da República que, mediante um processo político baseado em "leituras elásticas" da CF/1988 sinaliza que os institutos democráticos evidenciados na $\mathrm{CF} / 1988$ deixaram de operar e, por consequência, o sistema político brasileiro não pode mais receber o título de “democrático", sequer numa compreensão menos exigente do termo (IBID, 2016).

\footnotetext{
$5 \quad$ Tal farsa a que se refere o autor constitui-se no processo de impedimento impetrado em 2 de dezembro de 2015 pelo então presidente da Câmara dos Deputados Eduardo Cunha contra a presidenta legitimamente eleita, Dilma Vana Roussef, sob alegação de crime de responsabilidade.
} 
Com o afastamento da presidenta, passou a ocupar o cargo de Presidente do Brasil o vice, Michel Temer (PMDB) que deu início a uma série de reformas que sinalizam para um substantivo retrocesso no que se refere às políticas sociais. Dentre elas, está a Emenda Constitucional 95 de 2016 “Teto dos Gastos Públicos" que institui Novo Regime Fiscal no âmbito dos Orçamentos Fiscal e da Seguridade Social da União, que vigorará por 20 exercícios financeiros, existindo limites individualizados para as despesas primárias de cada um dos três Poderes, do Ministério Público da União e da Defensoria Pública da União […].

A Nota Técnica $1^{6}$ da Associação Nacional de Pesquisa em Financiamento da Educação (FINEDUCA) aponta que a aprovação da referida Emenda "significa estrangular a educação pública brasileira e tornar letra morta o Plano Nacional de Educação, haja vista suas implicações no que tange, em particular, ao alcance das metas previstas nos planos, e de modo geral, no direito à educação”.

Houve uma ampla mobilização social contrária à aprovação da referida Emenda $\mathrm{n}^{\circ} 95$ quando ainda era Proposta de Emenda à Constituição (PEC). A consulta pública realizada no site $^{7}$ do Senado evidencia a opinião da população brasileira: 23.766 votos a favor e 345.656 votos contrários à aprovação da PEC. Mesmo com a diferença expressiva de votos, a consulta pública foi ignorada e a PEC foi aprovada e transformada na Emenda Constitucional n ${ }^{\circ} 95$ de 2016.

Sobre a viabilidade de alcançar as metas do Plano Nacional de Educação, previsto no Art. 214 da CF/1988, Amaral (2016) sinaliza a decretação de sua "morte”, visto as reduções fiscais que a Emenda Constitucional no 95 implicará. A Meta 20 "ampliar o investimento público em educação pública de forma a atingir, no mínimo, o patamar de $7 \%$ (sete por cento) do Produto Interno Bruto - PIB do País no $5^{\circ}$ (quinto) ano de vigência desta Lei e, no mínimo, o equivalente a 10\% (dez por cento) do PIB ao final do decênio” (Brasil, 2014) está "liquidada", pois impossibilita o cumprimento das metas do PNE (2014-2024), exatamente como ocorreu com o PNE (2001-2011) que teve todas as suas metas vinculadas aos recursos financeiros vetadas pelo presidente Fernando Henrique Cardoso (Amaral, 2016).

\footnotetext{
6 A Nota Técnica 1 da FINEDUCA está disponível em: <http://www.fineduca.org.br/wpcontent/uploads/2016/10/Nota-conjunta-FINEDUCA-CNDE_01_2016.pdf.>. Acesso em: 21 jun. 2016.

7 A pesquisa pode ser acessada em:

<https://www 12.senado.leg.br/ecidadania/visualizacaomateria?id=127337>. Acesso em: 21 jun. 2016.
} 
[...] Como garantir, por exemplo, o cumprimento da meta 20 do PNE se o Estado brasileiro estará impedido de aplicar "dinheiro novo" em políticas sociais, inclusive na educação? E a meta 17 do Plano decenal, como alcançála se o piso nacional do magistério terá seu valor real congelado por 20 anos? E como superar as limitações orçamentárias do Fundeb, sobretudo com o compromisso de incluir mais estudantes nas escolas, se a vinculação constitucional de impostos será suspensa por prazo que supera a vigência do atual PNE? Aliás, pelo novo formato fiscal [...] não há mais garantias de renovação do Fundeb, muito menos de instituição do CAQi e CAQ, podendo a educação sofrer enorme retrocesso (FNE, 2015, p.2).

Essas indagações se pautam na realidade futura imposta pela Emenda Constitucional n 95 de 2016 na medida em que trará grande prejuízo para o país e para a população que mais necessita dos serviços públicos de educação e a saúde. Sena (2016) evidencia que o prazo de 20 anos da Emenda, corresponde a cinco Planos Plurianuais ${ }^{8}$, previsto no Art. 165 da CF/1988 e a dois Planos Nacionais de Educação cujos reflexos incidirão no plano de 20142024 e, indubitavelmente, no PNE (2024-2034).

O autor destaca a tríplice dimensão do PNE: a) política de Estado: para além de governos, visto a Emenda Constitucional n $n^{0} 59$ qualificá-lo como decenal e organizador do SNE; b) regra jurídica: gera obrigações que podem ser exigidas judicialmente, principalmente se atingirem o núcleo essencial do direito à da educação. Portanto, o PNE não é uma mera carta de intenções e; c) pacto político: pacto em prol da educação, cuja elaboração envolveu um número recorde de participantes, de emendas e foi exaustivamente discutido pela sociedade (SENA, 2016).

Essa tríplice capacidade do PNE não é considerada pela Emenda Constitucional nº 95 de 2016 na medida em inviabiliza as metas e estratégias constantes nos planos e adia os avanços dos direitos sociais historicamente conquistados por àqueles que acreditam e defendem a educação pública.

É importante registrar que o ordenamento jurídico brasileiro as Constituições Federais de 1934, 1961 e 1988, bem como na LDB, Lei nº 9.394/96, consagram a ideia de um Plano Nacional de Educação. No entanto, a luta histórica com vistas à implementação de um plano de estado da educação nacional, configura-se sob grandes desafios, sobretudo no contexto do financiamento da educação, em geral e, em particular, dos planos decenais de educação.

\footnotetext{
$8 \quad$ Instrumento de planejamento que define as prioridades do governo e deve contemplar as diretrizes, objetivos e metas da administração pública federal.
} 
Nesse contexto, Farenzena (2001) destaca que o financiamento da educação é um dos temas centrais da política educacional brasileira. Embora a temática seja discutida sob diferentes enfoques, há um consenso em relação a dois pontos críticos: o planejamento da ampliação do fundo público destinado à educação pública e a regulamentação do regime de colaboração, visto as capacidades financeira e administrativa dos entes subnacionais diferenciarem-se substancialmente.

"Para as definições específicas do financiamento convergem e divergem, na atualidade, muitas das concepções de organização da educação e de distribuição de encargos e poder decisório para a formulação e implementação de planos, projetos e ações” (IBID, 2001, p.22). Embora juridicamente previsto desde a década de 1930, apenas os dois últimos planos, isto é, o PNE 2001-2010, Lei $n^{\circ}$. 10.172/2001 e o PNE 2014-2024, aprovado pela Lei $n^{\circ}$. 13.005/2014 detiveram respaldo legal e trataram de modo específico, a questão do financiamento da educação.

Dessa forma, a compreensão do financiamento da educação exige uma identificação de como os gastos públicos se configuram, sobretudo em decorrência das prioridades dos diferentes contextos históricos com seus respectivos governantes (Conceição, 2016).

As metas e estratégias destinadas ao financiamento da educação em ambos os planos foram alvos, em diferentes contextos, de interesses conflituosos, cujo resultado infere no descumprimento das disposições legais.

Se, no caso do PNE (2001-2010) os impasses se iniciaram com os vetos do então presidente Fernando Henrique Cardoso ao percentual do Produto interno Bruto destinado à educação, no caso do PNE (2014-2024) as ingerências em torno da destinação dos recursos públicos para a iniciativa privada, bem como a aprovação da Emenda Constitucional n ${ }^{\circ} 95$ de 2016, sinaliza, mais uma vez, a descontinuidade dos anseios conclamados nos planos decenais de educação.

Por consequência, consubstanciam, novamente, os não avanços no campo educacional às intempéries de cunho político-partidário que, historicamente, inviabilizam a consolidação dos planos nacionais de educação, seja por golpes de estado, seja pela insuficiência de recursos destinados à efetivação da educação enquanto um direito social.

\section{Considerações finais}


Os avanços normativos inaugurados com a CF/1988 são inegáveis no campo dos Direitos Sociais, sobretudo para a educação. No entanto, faz-se necessário o desenvolvimento de ações conjuntas ou negociadas entre os diferentes entes subnacionais, visto suas responsabilidades e capacidades financiadoras serem diferenciadas.

$\mathrm{O}$ atual momento histórico traz sérias implicações à efetivação da educação como um direito social e, nesse ínterim, aos planos educacionais, bem como fragiliza demasiadamente os processos de construção democrática das políticas públicas, conquistados a partir da $\mathrm{CF} / 1988$. Embora exista dispositivos na própria Constituição direcionados à proteção dos anseios dos constituintes, nota-se que as Emendas Constitucionais, em determinados casos, têm contrariado os dispositivos constitucionais garantidores destinados à consolidação e ao avanço dos Direitos Sociais, sobretudo no contexto da Emenda Constitucional 95 de 2016 que institui novo regime fiscal.

\section{Referências}

AMARAL, Nelson Cardoso. PEC 241: a "morte" do PNE (2014-2024) e o poder de diminuição dos recursos educacionais. Revista Brasileira de Política e Administração da Educação. V. 32, n. 3, p. 653 - 673 set./dez. 2016.

BRASIL. Palácio do Planalto. Emendas a Constituição. 2018. Disponível em: <http://www.planalto.gov.br/ccivil_03/constituicao/emendas/emc/quadro_emc.htm>. Acesso em: 20 de junho de 2018.

Palácio do Planalto. Constituição da República Federativa do Brasil de 1988. Disponível em: <http://www.planalto.gov.br/ccivil_03/constituicao/constituicaocompilado.

htm>. Acesso em: 19 de junho de 2018.

Palácio do Planalto. Lei $n^{\circ} 13.005$ de 25 de junho de 2014. Aprova o Plano Nacional de Educação e dá outras providências. Disponível em: <http://www.planalto.gov.br/ccivil_03/_ato2011-2014/2014/lei/113005.htm>. Acesso em: 20 jun. 2018.

Ministério da Educação. Sobre o FUNDEB. 2018. Disponível em: <http://www.fnde.gov.br/financiamento/fundeb>. Acesso em: 21 ago. 2018.

CONCEIÇÃO. Sérgio Henrique da. Perspectivas e desafios do Plano Nacional de Educação (PNE-2014-2024) no contexto do financiamento da educação básica. Educação em Revista. V.17.n.17.jan./jun.2016. 
CURY, Carlos Roberto Jamil. O princípio da Gestão Democrática na educação: gestão democrática da educação pública. In: BRASIL, Ministério da Educação. Gestão democrática da educação. Boletim 19, outubro 2005. Salto para o Futuro. TV Escola. p.14-19.

FARENZENA, Nalu. Diretrizes da política de financiamento da educação básica brasileira: continuidades e inflexões no ordenamento constitucional legal (1987-1996). 2001. 259 f. Tese (Doutorado em Educação) - Universidade Federal do Rio Grande do Sul, Porto Alegre, 2001. Disponível em: <https://www.lume.ufrgs.br/bitstream/handle/10183/1903/000311896.pdf? sequence=1. Acesso em: 03 jul. 2018.

FERNANDES, Maria Dilnéia Espíndola. Gestão da educação básica em Mato Grosso do Sul nos anos 1990. Revista Brasileira de Política e Administração da Educação. V.24, n.3, p.517-533, set/dez. 2008. Disponível em: <www.seer.ufrgs.br/rbpae/article/download/19270/11193 >. Acesso em: 14 jun. 2018.

FORUM NACIONAL DE EDUCAÇÃO (FNE). 44 $4^{a}$ Nota Pública do Fórum Nacional de Educação - PEC 241 que inviabiliza as metas do Plano Nacional de Educação. 2015. Disponível em: <http://www.anped.org.br/news/entrevista-com-paulo-sena-pec-241>. Acesso em: 21 jun. 2018.

GOMES, Ciro. Por que o golpe acontece. In: JINKINGS, Ivana; DORIA, Kim; CLETO, Murilo. (Orgs.) Por que gritamos o golpe? Para entender o impeachment e a crise política no Brasil. São Paulo, SP: Boitempo, 2016.

LÖWI, Michael. Da tragédia à farsa. O golpe de 2016 no Brasil. In: JINKINGS, Ivana; DORIA, Kim; CLETO, Murilo. (Orgs.) Por que gritamos o golpe? Para entender o impeachment e a crise política no Brasil. São Paulo, SP: Boitempo, 2016.

NOGUEIRA, Octaviano. A Constituição de 1824. 3.ed. Brasília: Senado Federal, 2012. (Coleção Constituições brasileiras).

OLIVEIRA, Rosimar de Fátima. O FUNDEF ao FUNDEB: o processo político de Fomulação da emenda constitucional $n^{\circ}$ 53/2006. Jornal de políticas educacionais. $\mathrm{n}^{\circ}$ 5. Jan. jun. 2009. p. 50-58. Disponível em: <http://www.jpe.ufpr.br/n5_5.pdf>. Acesso em: 21 ago. 2018.

PINHEIRO, Maria Francisca. O público e o privado na educação: um conflito fora de moda? In: FÁVERO, Osmar. A educação nas constituintes brasileiras: 1823-1988. Campinas, SP: Autores Associados, 1996. (Coleção memória da educação).

SARLET, Ingo Wolfgang. MARINONI, Luiz Guilherme. MITIDIERO, Daniel. Curso de Direito Constitucional. 6. ed. São Paulo, SP: Saraiva, 2017.

SENA, Paulo. Impactos da PEC 241 no financiamento da educação. Disponível em: https://drive.google.com/file/d/oB-XDy 1sMnkq5UXhQN3JLemFwUUE/view. Acesso em: 19 jun. 2016. 
Revista Educação e Políticas em Debate - v. 7, n. 2, p. 313-327, mai./ago. 2018 - ISSN 2238-8346

SOUZA, Celina. Federalismo, Desenho constitucional e instituições federativas no Brasil Pós 1988. Revista de Sociologia e Política. n.24. Curitiba. 2005 (p. 105-121). Disponível em: $<$ file:///C:/Users/particcular/Downloads/3719-7553-1-PB.pdf>. Acesso em 14 jun. 2018. 